\title{
Observation of the impact of the eight-step process combined with the four-track crossover quality control applied to patients with glioma surgery: a randomised trial
}

\author{
Zhen Zhang", Jing Ma", Ying Xu, Huihui Zhang \\ Department of Neurosurgery, The First Affiliated Hospital of Soochow University, Suzhou, China \\ Contributions: (I) Conception and design: All authors; (II) Administrative support: Y Xu, H Zhang; (III) Provision of study materials or patients: Z \\ Zhang, J Ma; (IV) Collection and assembly of data: Z Zhang, J Ma; (V) Data analysis and interpretation: All authors; (VI) Manuscript writing: All \\ authors; (VII) Final approval of manuscript: All authors. \\ "These authors contributed equally to this work. \\ Correspondence to: Ying Xu; Huihui Zhang. Department of Neurosurgery, The First Affiliated Hospital of Soochow University, 188 Shizi Street, Gusu \\ District, Suzhou 215006, China. Email: xuying2005@suda.edu.cn; 672882751@qq.com.
}

Background: At present, surgery is the main treatment for patients with glioma, but there are certain risks in the operation. The traction and stress reaction of related brain tissue during surgery can cause complications such as cerebral edema, which adversely affects the prognosis of patients. The purpose of the present study was to explore the effect of an eight-step process combined with four-track quality control applied to patients undergoing glioma surgery.

Methods: A total of 122 patients undergoing glioma surgery admitted to our hospital from March 2017 to March 2020 were selected and divided into two groups according to the random number table method, each with 61 cases. The control group underwent routine intervention after surgery and the observation group underwent an eight-step process combined with four-track cross-over quality control intervention after surgery. The postoperative rehabilitation effects, cancer-related fatigue, changes in quality of life, and the incidence of complications before and after intervention were compared between the two groups.

Results: The time of catheter removal, the time of first eating, the time of getting out of bed, and the length of hospital stay of the observation group were shorter than those of the control group $(\mathrm{P}<0.05)$. In the observation group cognitive fatigue, physical fatigue, and emotional fatigue scores were lower than those of the control group after intervention $(\mathrm{P}<0.05)$ and the quality-of-life scores of the observation group after intervention were higher than those of the control group $(\mathrm{P}<0.05)$. The total incidence of complications in the observation group was lower than that of the control group $(\mathrm{P}<0.05)$.

Conclusions: The eight-step process combined with four-track quality control applied to patients undergoing glioma surgery can reduce cancer-related fatigue, improve quality of life, reduce complications, and promote speedy recovery.

Keywords: Eight-step process; four-track quality control; glioma; rehabilitation; cancer-related fatigue; quality of life; complications

Submitted Feb 23, 2021. Accepted for publication Apr 17, 2021.

doi: $10.21037 / \mathrm{atm}-21-1228$

View this article at: http://dx.doi.org/10.21037/atm-21-1228 


\section{Introduction}

Gliomas are neural tumors which constitute about $46 \%$ of all intracranial tumors (1). At present, the pathogenesis of glioma is not clear, it is a typical abnormal gene expression tumor, there are a lot of abnormal gene expression. Some researchers collected glioma tissues and normal brain tissues for microarray analysis, and found 476 differentially expressed circRNAs (2) and more than 600 differentially expressed lncRNAs (3) in glioma tissues and brain tissues. However, the role in the pathogenesis remains to be studied. Surgical treatment is recognized as the most effective method for the treatment of glioma, which advocates safe and wide range of tumor resection. Due to the growth mode of glioma cells is diverse and infiltrating, and it is difficult to distinguish the boundary between tumor and normal brain tissue during surgery, it is difficult to achieve total tumor resection. With the continuous development of modern medicine, including the application of new technologies such as multimodal magnetic resonance imaging technology, intraoperative electrophysiological detection, fluorescence guidance technology, intraoperative wake-up, intraoperative neuronavigation etc. to provide maximum safe tumor resection possible $(4,5)$. Postoperative patients with glioma are subject to both physical and psychological stress. The psychological burden of patients is large, and cancerrelated fatigue occurs easily, which affects the treatment effect and results in a significant decline in the quality of life (6). Microsurgery has obvious advantages in improving patients' cognition and quality of life (7). Although routine postoperative care can achieve certain results, there are still many shortcomings. The eight-step process summarizes the various interventions after surgery and formulates corresponding standardized processes which allow intervention staff to implement postoperative care according to the process, thereby reducing nursing errors (8). The fourtrack crossover quality control can effectively control and improve nursing quality and help patients recover as soon as possible (9). This study is designed to develop an eightstep process for patients with glioma, formulate the process of postoperative care in chronological order, and train and assess nursing staff. At the same time, four-track crossover quality control is used for various postoperative care of glioma. Comprehensive monitoring of work is helpful for nursing staff to complete nursing tasks according to quality control content and reduce nursing vacancies. At the same time, through multi-level cross-over quality control, the gaps in the work can be found and remedied in time, so as to fully understand the inner condition of patients and make decisions Accurate evaluation and provide professional psychological counseling to promote the elimination of common anxiety and depression. The purpose of the present study was to explore the effect of an eight-step process combined with four-track quality control applied to patients undergoing glioma surgery.

We present the following article in accordance with the CONSORT reporting checklist (available at http://dx.doi. org/10.21037/atm-21-1228).

\section{Methods}

\section{Patient selection}

A total of 122 patients undergoing glioma surgery admitted to our hospital from March 2017 to March 2020 were selected and divided into two groups according to the random number table method, each with 61 cases. The inclusion criteria were as follows: (I) age between 18-60 years old; (II) patients were diagnosed as glioma by imaging examination; (III) surgery was successfully completed; (IV) the patient's consciousness was clear; (V) the patients and their families signed informed consent documents. The exclusion criteria were as follows: (I) patients with other tumors; (II) patients with severe infection; (III) patients with a history of craniocerebral trauma surgery; (IV) patients with mental abnormalities; (V) patients with cognitive impairment; (VI) patients with poor compliance. The study was approved by the Ethics Committee of The First Affiliated Hospital of Soochow University and conducted in accordance with the Declaration of Helsinki (as revised in 2013). All subjects provided informed consent.

\section{Interventions}

The control group received routine intervention, including postoperative routine intervention, psychological support, and related nursing care for postoperative complications.

Through consulting relevant literature combined with past clinical experience, an eight-step process combined with four-track cross-over quality control intervention was established for the observation group, and comprised the following: (I) after the operation room nurses escorted the patients back to the ward, they handed over the patients face to face with the responsible nurses. The responsible nurses fully mastered the operation conditions of the patients and made relevant records. The operation room nurses and the responsible nurses consulted and then entered notes and signed the clinical record together. 
(II) Intervention staff helped the patients lay in the sidelying position with the healthy side up and raised the bed head angle to $15-30^{\circ}$ while maintaining a stable blood pressure and conscious state in patients. The intervention staff assisted patients to turn over within 24 hours after the operation, advised them to avoid coughing as much as possible, and explained the importance and significance of each postoperative intervention to improve compliance. (III) Intervention staff implemented close monitoring of each patient's vital indicators, used the Glasgow coma score, and immediately notified doctors and recorded any significant increase in intracranial pressure. (IV) Intervention staff regularly observed whether the patient's incision had oozing or seepage, changed the dressing in a timely manner, and fixed the indwelling drainage tube at the same level of the patient's head after the operation. The patient's urinary catheter was removed between 6 hours and 24 hours after their awakening from anesthesia, and the drainage bag was clamped for patients who needed to be transported. (V) Intervention staff strengthened the respiratory management of patients after the operation by giving continuous oxygen inhalation at $2 \mathrm{~L} / \mathrm{min}$, patted the patients on their backs, and turned them over regularly to avoid complications such as lung infections. (VI) Patients were given a 2,000 mL fluid infusion on the first day after operation. The amount of rehydration was then gradually reduced from the second day and stopped on the third day. Patients could be given a $250 \mathrm{~mL}$ nutrient solution 6 hours after operation, liquid food could be given on the first day after operation, and normal food could be taken on the second day after operation. (VII) After the patient was awake after anesthesia, intervention staff guided them to perform exercises such as extension and flexion of the lower limbs and ankle pump current. After 1 day, if progressing appropriately, patients could get out of bed and perform dyskinesia limb function under the guidance of intervention staff. (VIII) During the handover, the intervention staff of each class recorded the changes in the patient's condition in detail and cooperated with each other, to provide comprehensive care for each patient. The fourtrack cross-over quality control involved the self-inspection track of intervention personnel, the review track of shift handover, the mutual inspection track of shift personnel, and the mobile detection track of management personnel. The quality control table of postoperative nursing of glioma was designed, which mainly including micturition nursing, respiratory tract management, posture nursing, condition monitoring, ward management, medication nursing, drainage tube nursing, surgical incision nursing, and urination nursing. If the above quality control items were not completed, this was recorded as a nursing omission and corresponding measures were taken to address the matter. Intervention staff summarized and analyzed the occurrence of nursing defects every week and discussed and formulated effective corrective measures when required.

\section{Evaluation indexes}

\section{Postoperative rehabilitation effect}

The catheter removal time, initial eating time, time of getting out of bed, and hospitalization time were recorded.

\section{Cancer-related fatigue}

The Cancer-related Fatigue Scale (CRFS) was used to evaluate cancer-related fatigue. The CRFS includes three dimensions, fifteen entries, each entry is allocated $0-4$ points, and the total score is $0-60$ points. A lower total score indicates less cancer-related fatigue (10).

\section{The Quality of life}

The Generic Quality of Life Inventory-74 (GQOLI-74) was used to evaluate the quality of life. GQOLI-74 includes four dimensions, each with $0-100$ points, and a higher score indicate a higher quality of life (11).

\section{Complication}

The incidence of postoperative hyperthermia, deep vein thrombosis, pulmonary infection, secondary epilepsy, intracranial hemorrhage, and other complications were calculated.

\section{Statistical analyses}

Statistical analysis was performed using SPSS version 20.0 (IBM, Armonk, NY, USA). Postoperative rehabilitation effect, Cancer-related fatigue, and Quality of life were expressed as mean \pm standard deviation and compared using 2 -tailed $t$-tests. Complication rates were expressed by rates and percentages and compared using the $\chi^{2}$-test or ranksum test, and $\mathrm{P}<0.05$ was considered statistically significant.

\section{Results}

\section{General information}

This study included 122 patients undergoing glioma surgery. In the control group, there were 33 males and 28 females, 
Table 1 Comparison of general information between the two groups

\begin{tabular}{|c|c|c|c|c|}
\hline Item & Control group $(n=61)$ & Observation group $(n=61)$ & $t / \chi^{2}$ & $P$ value \\
\hline Gender, n (\%) & & & 0.133 & 0.715 \\
\hline Male & $33(54.10)$ & $35(57.38)$ & & \\
\hline Female & $28(45.90)$ & 26 (42.62) & & \\
\hline Stage I & $14(22.95)$ & $15(24.59)$ & & \\
\hline Stage II & $23(37.70)$ & 26 (42.62) & & \\
\hline Stage III & $14(22.95)$ & $12(19.67)$ & & \\
\hline Stage IV & $10(16.39)$ & $8(13.11)$ & & \\
\hline Parietal lobe & $13(21.31)$ & $15(24.59)$ & & \\
\hline Temporal lobe & $11(18.03)$ & $12(19.67)$ & & \\
\hline Occipital lobe & $7(11.48)$ & $6(9.84)$ & & \\
\hline
\end{tabular}

and the age ranged from 24-59 years old, with an average age of $(49.27 \pm 7.44)$ years. There were 14 cases in stage I, 23 cases in stage II, 14 cases in stage III, and 10 cases in stage IV, and the lesion was located in the frontal lobe in 30 patients, the parietal lobe in 13 patients, the temporal lobe in 11 patients and the occipital lobe in seven. The observation group was comprised of 35 males and 26 females and the age

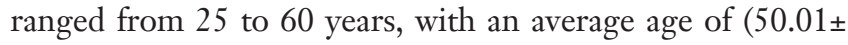
7.59 ) years. In this group there were 15 cases in stage I, 26 cases in stage II, 12 cases in stage III, and eight cases in stage IV and the lesion was in the frontal lobe in 28 patients, the parietal lobe in 15 patients, the temporal lobe in 12 patients and the occipital lobe in 6 patients. There were no statistically significant differences between the two groups in general data such as gender, age, clinical stage, and lesion location $(\mathrm{P}>0.05)$ as shown in Table 1.

\section{Postoperative rehabilitation effect}

The catheter removal time in the observation group was $16.03 \pm 4.07$ hours, which was significantly shorter than that in the control group 19.75 \pm 4.16 hours $(\mathrm{t}=4.992, \mathrm{P}=0.000)$, and the initial eating time of the observation group was $10.25 \pm 2.04$ hours, which was also significantly shorter than that of the control group 13.16 \pm 2.17 hours ( $t=7.631$, $\mathrm{P}=0.000)$. The time of getting out of bed of the observation group was $1.75 \pm 0.42$ days, which was significantly shorter than that of the control group $2.26 \pm 0.49$ days $(t=6.172$, $\mathrm{P}=0.000)$ and the hospitalization time of the observation group was $8.36 \pm 1.55$ days, which was also significantly shorter than that of the control group $9.94 \pm 1.87$ days $(\mathrm{t}=5.081, \mathrm{P}=0.000)$. See Table 2 for details.

\section{Cancer-related fatigue}

Before intervention, there were no significant differences in the scores for cognitive fatigue, physical fatigue, and emotional fatigue between the observation group and the control group $(t=0.298,0.348,0.895$, respectively; $\mathrm{P}=0.766$, $0.728,0.373$, respectively). However, after the intervention, the scores for each fatigue category in the observation group were lower than those in the control group ( $t=12.430$, $10.287,17.458$, respectively; $\mathrm{P}=0.000,0.000,0.000$, respectively). See Table 3 for details.

\section{The quality of life}

Before intervention, there were no significant differences in the scores of psychological function, physical function, material function, and social function between the observation group and the control group $(\mathrm{t}=0.204,0.404$, $0.083,0.235$, respectively; $\mathrm{P}=0.839,0.687,0.934,0.815$, 
Table 2 Comparison of postoperative rehabilitation effect between the two groups

\begin{tabular}{|c|c|c|c|c|}
\hline Group & The catheter removal time (h) & The initial eating time $(\mathrm{h})$ & The time of getting out of bed (d) & The hospitalization time (d) \\
\hline $\begin{array}{l}\text { Observation group } \\
(n=61)\end{array}$ & $16.03 \pm 4.07$ & $10.25 \pm 2.04$ & $1.75 \pm 0.42$ & $8.36 \pm 1.55$ \\
\hline $\mathrm{t}$ value & 4.992 & 7.631 & 6.172 & 5.081 \\
\hline
\end{tabular}

Table 3 Comparison of cancer-related fatigue between the two groups before and after intervention (points)

\begin{tabular}{|c|c|c|c|c|}
\hline Time & Group & Cognitive fatigue & Physical fatigue & Emotional fatigue \\
\hline \multirow{3}{*}{ Before intervention } & Observation group $(n=61)$ & $7.92 \pm 1.07$ & $12.47 \pm 2.41$ & $9.98 \pm 1.79$ \\
\hline & $\mathrm{t}$ value & 0.298 & 0.348 & 0.895 \\
\hline & $P$ value & 0.766 & 0.728 & 0.373 \\
\hline \multirow{3}{*}{ After intervention } & Observation group $(n=61)$ & $3.45 \pm 0.68$ & $6.22 \pm 1.05$ & $4.35 \pm 0.72$ \\
\hline & $\mathrm{t}$ value & 12.430 & 10.287 & 17.458 \\
\hline & $P$ value & 0.000 & 0.000 & 0.000 \\
\hline
\end{tabular}

Table 4 Comparison of quality of life between the two groups before and after intervention (points)

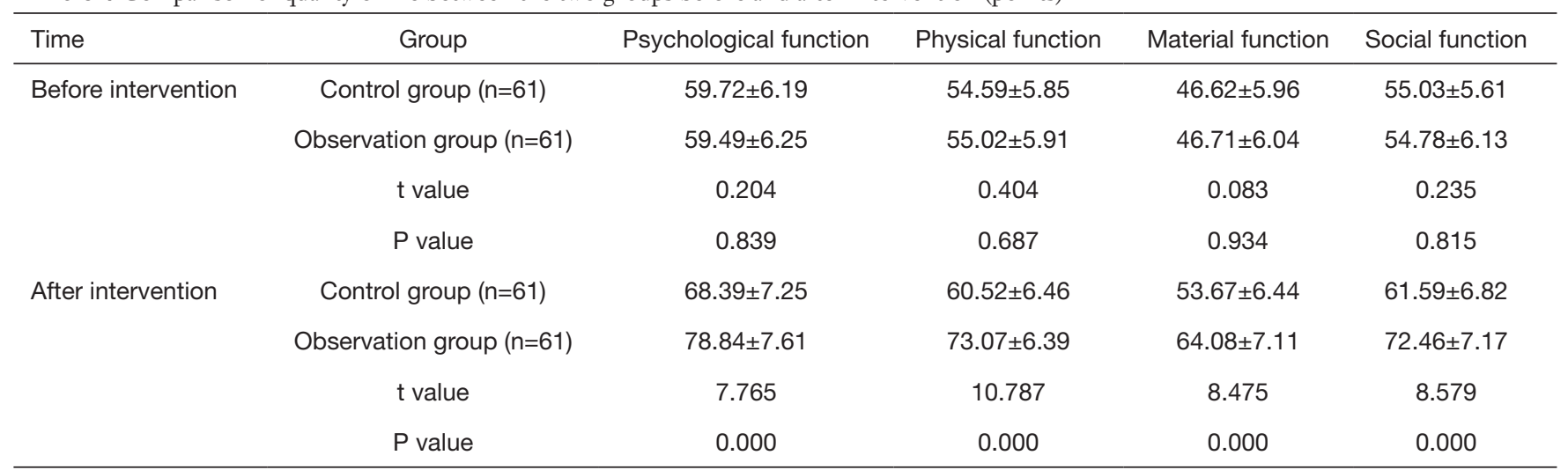

respectively). After the intervention, the scores in each function category in the observation group were higher than those in the control group $(\mathrm{t}=7.765,10.787,8.475,8.579$, respectively; $\mathrm{P}=0.000,0.000,0.000,0.000$, respectively). See Table 4 for details.

\section{Complication rate}

In the observation group, there was one case of postoperative hyperthermia and one case of pulmonary infection, and the total incidence of complications was $3.28 \%$. In the control group, there were two cases of postoperative hyperthermia, four cases of deep vein thrombosis, three of pulmonary infection, one of secondary epilepsy and three cases of intracranial hemorrhage, and the total incidence of complications was $21.31 \%$. Compared with the two groups, the total incidence of complications in the observation group was significantly lower than that in the control group 
Table 5 Comparison of the incidence of complications between the two groups

\begin{tabular}{|c|c|c|c|c|c|c|}
\hline Group & $\begin{array}{c}\text { Postoperative } \\
\text { hyperthermia, n (\%) }\end{array}$ & $\begin{array}{c}\text { Deep vein } \\
\text { thrombosis, } \mathrm{n}(\%)\end{array}$ & $\begin{array}{c}\text { Pulmonary } \\
\text { infection, } \mathrm{n}(\%)\end{array}$ & $\begin{array}{c}\text { Secondary } \\
\text { epilepsy, n (\%) }\end{array}$ & $\begin{array}{c}\text { Intracranial } \\
\text { hemorrhage, n (\%) }\end{array}$ & $\begin{array}{l}\text { The total incidence of } \\
\text { complications, } \mathrm{n}(\%)\end{array}$ \\
\hline Control group $(n=61)$ & $2(3.28)$ & $4(6.56)$ & $3(4.92)$ & $1(1.64)$ & $3(4.92)$ & $13(21.31)$ \\
\hline $\begin{array}{l}\text { Observation group } \\
(n=61)\end{array}$ & $1(1.64)$ & $0(0.00)$ & $1(1.64)$ & $0(0.00)$ & $0(0.00)$ & $2(3.28)$ \\
\hline$\chi^{2}$ value & 0.342 & 2.326 & 0.258 & 1.008 & 1.367 & 9.198 \\
\hline
\end{tabular}

$\left(\chi^{2}=9.198, \mathrm{P}=0.002\right)$. See Table 5 for details.

\section{Discussion}

While surgical treatment is currently the main treatment for patients with glioma, there are certain risks in the operation. The traction and stress reaction of related brain tissue during surgery can cause complications such as cerebral edema, which in turn affects the prognosis of patients $(12,13)$. Postoperative cognitive dysfunction (POCD) refers to the slight damage to the brain's advanced cortical function after anesthesia and surgery, which affects the patient's memory, attention and information processing capabilities, and is a mild neurocognitive disorder. POCD not only reduces the quality of postoperative recovery and prolongs the length of hospitalization, but also leads to permanent cognitive dysfunction in individual cases, which reduces the quality of life of patients (14). Therefore, the selection of appropriate anesthetics may be of great significance in reducing the incidence of POCD in patients undergoing meningioma resection. At the same time, due to the complexity of postoperative nursing work, intervention staff are prone to nursing omissions in daily nursing, which not only affects the postoperative recovery of patients, but also causes medical disputes (15). Standardized nursing according to the intervention process can effectively reduce surgical complications help patients quickly recover (16). This study achieved good results by implementing an eightstep process combined with four-track cross-over quality control interventions for postoperative patients with glioma.

The catheter removal time, initial eating time, time of getting out of bed, and hospitalization time of the observation group were shorter than those of the control group $(\mathrm{P}<0.05)$. This showed the eight-step process combined with four-track cross-over quality control interventions could effectively promote the postoperative recovery of patients with glioma. This is because the eight- step process interventions formulate a scientific nursing process, allowing intervention staff to quickly grasp the key points when implementing nursing operations and reducing nursing errors $(17,18)$. Further, the use of the four-track cross-over quality control intervention in the nursing process involving features such as vital signs monitoring, complications prevention, and pipeline management can not only implement real-time monitoring of postoperative nursing work, but also supervise and intervene to complete various postoperative nursing tasks avoiding nursing omissions (19). In addition, the four-track cross-over quality control can detect problems in nursing work in time and implement corresponding remedial measures to help patients recover as soon as possible after surgery (20).

The results of this study also showed that the scores of cognitive fatigue, physical fatigue, and emotional fatigue in the observation group were lower than those in the control group $(\mathrm{P}<0.05)$. It showed that the eightstep process combined with four-track cross-over quality control interventions could effectively alleviate cancerrelated fatigue, which, as a high-incidence symptom of malignant tumors not only triggers subjective fatigue, but also adversely affects the daily life and social functions of patients. The eight-step process combined with four-track cross-over quality control interventions can effectively improve the level of nursing and promote the postoperative rehabilitation of patients, to improve the subjective feelings of patients and alleviate cancer-related fatigue $(21,22)$.

In addition, the quality-of-life scores of the observation group after intervention were higher than those of the control group and the total incidence of complications in the observation group was lower than that of the control group $(\mathrm{P}<0.05)$. This showed the eight-step process combined with four-track cross-over quality control interventions could improve the quality of life of patients and reduce complications. The eight-step process can provide clear intervention clues for intervention staff, 
and the four-track cross-over quality control can build a nursing error and omission patch system, which enables staff to implement patient postoperative care more closely and carefully. This reduces the incidence of postoperative complications, promotes improvement of the patients' condition, and improves their quality of life $(23,24)$. The postoperative quality of life of patients with glioma is the focus of clinical attention at this stage, and clinicians usually pay insufficient attention to this. Zhou et al. (25) found that patients with glioma at different times after the operation through follow-up and analysis There are significant differences in the quality of life. The influencing factors include age, intraoperative blood loss, and degree of tumor resection. It can be seen that surgery has a greater impact on the quality of life of patients. Improving the postoperative care plan is of great significance to improving the quality of life of patients after surgery.

\section{Conclusions}

The eight-step process combined with a four-track quality control applied to patients undergoing glioma surgery can reduce cancer-related fatigue, improve quality of life, reduce complications, and promote speedy recovery.

\section{Acknowledgments}

Funding: None.

\section{Footnote}

Reporting Checklist: The authors have completed the CONSORT reporting checklist. Available at http://dx.doi. org/10.21037/atm-21-1228

Data Sharing Statement: Available at http://dx.doi. org/10.21037/atm-21-1228

Conflicts of Interest: All authors have completed the ICMJE uniform disclosure form (available at http://dx.doi. org/10.21037/atm-21-1228). The authors have no conflicts of interest to declare.

Ethical Statement: The authors are accountable for all aspects of the work in ensuring that questions related to the accuracy or integrity of any part of the work are appropriately investigated and resolved. The study was approved by the Ethics Committee of The First Affiliated
Hospital of Soochow University and conducted in accordance with the Declaration of Helsinki (as revised in 2013). All subjects provided informed consent.

Open Access Statement: This is an Open Access article distributed in accordance with the Creative Commons Attribution-NonCommercial-NoDerivs 4.0 International License (CC BY-NC-ND 4.0), which permits the noncommercial replication and distribution of the article with the strict proviso that no changes or edits are made and the original work is properly cited (including links to both the formal publication through the relevant DOI and the license). See: https://creativecommons.org/licenses/by-nc-nd/4.0/.

\section{References}

1. King AR, Corso CD, Chen EM, et al. Local DNA Repair Inhibition for Sustained Radiosensitization of High-Grade Gliomas. Mol Cancer Ther 2017;16:1456-69.

2. Song $X$, Zhang N, Han P, et al. Circular RNA profile in gliomas revealed by identification tool UROBORUS. Nucleic Acids Res 2016;44:e87.

3. Han L, Zhang K, Shi Z, et al. LncRNA profile of glioblastoma reveals the potential role of lncRNAs in contributing to glioblastoma pathogenesis. Int J Oncol 2012;40:2004-12.

4. Halkett GKB, Lobb EA, Rogers MM, et al. Predictors of distress and poorer quality of life in High Grade Glioma patients. Crit Care Nurs Clin North Am 2017;29:157-65.

5. Sirachainan N, Boongird A, Swangsilpa T, et al. Reported outcomes of children with newly diagnosed high-grade gliomas treated with nimotuzumab and irinotecan. Childs Nerv Syst 2017;33:893-7.

6. Chun SJ, Park SH, Park CK, et al. Survival gain with re$\mathrm{Op} / \mathrm{RT}$ for recurred high-grade gliomas depends upon risk groups. Radiother Oncol 2018;128:254- 9.

7. Prabhu RS, Won M, Shaw E G, et al. Effect of the addition of chemotherapy to radiotherapy on cognitive function in patients with low-grade glioma: Secondary analysis of RTOG 98-02. J Clin Oncol 2014;32:535-41.

8. Li J, Li HY, Liu JH, et al. The Clinical Implications of Human Telomerase Reverse Transcriptase Expression in Grade and Prognosis of Gliomas: a Systematic Review and Meta-analysis. Mol Neurobiol 2016;53:2887-93. Retraction in: Mol Neurobiol 2017;54:7552.

9. Cimino PJ, Zager M, McFerrin L, et al. Multidimensional scaling of diffuse gliomas: application to the 2016 World Health Organization classification system with 
prognostically relevant molecular subtype discovery. Acta Neuropathol Commun 2017;5:39.

10. Amano K, Suzuki K. The process of life adjustment in patients at onset of glioma who are receiving continuous oral anticancer drug: A qualitative descriptive study. Int J Nurs Sci 2018;6:134-40.

11. Picart T, Armoiry X, Berthiller J, et al. Is fluorescenceguided surgery with 5-ala in eloquent areas for malignant gliomas a reasonable and useful technique. Neurochirurgie 2017;63:189-96.

12. Kesler SR, Harrison RA, Petersen ML, et al. Pre-surgical connectome features predict IDH status in diffuse glioma. Oncotarget 2019;10:6484-93.

13. Barz A, Noack A, Baumgarten P, et al. Motor cortex reorganization in glioma patients assessed by repeated nTMS-a longitudinal study. World Neurosurg 2018;112:e442-53.

14. Krenk L, Rasmussen LS, Kehlet H. New insights into the pathophysiology of postoperative cognitive dysfunction. Acta Anaesthesiol Scand 2010;54:951-6.

15. Yahanda AT, Patel B, Shah AS, et al. Impact of Intraoperative Magnetic Resonance Imaging and Other Factors on Surgical Outcomes for Newly Diagnosed Grade II Astrocytomas and Oligodendrogliomas: A Multicenter Study. Neurosurgery 2020;88:63-73.

16. Jamshidi AM, Eichberg DG, Komotar RJ, et al. Safety Analysis of Bilateral Laser Interstitial Thermal Therapy for Treatment of Butterfly Glioma. World Neurosurg 2020;144:e156-63.

17. Davis ME, Bossert D, Manne M. Toward Precision Medicine: Promising Areas of Research in Glioma. Semin Oncol Nurs 2018;34:569-72.

Cite this article as: Zhang $\mathrm{Z}, \mathrm{Ma} \mathrm{J}, \mathrm{Xu} \mathrm{Y,} \mathrm{Zhang} \mathrm{H}$. Observation of the impact of the eight-step process combined with the four-track crossover quality control applied to patients with glioma surgery: a randomised trial. Ann Transl Med 2021;9(8):696. doi: 10.21037/atm-21-1228
18. Planeta K, Setkowicz Z, Janik-Olchawa N, et al. Comparison of Elemental Anomalies Following Implantation of Different Cell Lines of Glioblastoma. ACS Chem Neurosci 2020;11:4447-59.

19. Serventi J, Behr J. Surgery and Evidence-based Treatments in Patients with Newly Diagnosed High-grade Glioma. Semin Oncol Nurs 2018;34:443-53.

20. Pessina F, Navarria P, Bellu L, et al. Treatment of patients with glioma during the COVID-19 pandemic: what we learned and what we take home for the future. Neurosurg Focus 2020;49:E10.

21. Mathur R, Zhang Y, Grimmer MR, et al. MGMT promoter methylation level in newly diagnosed low-grade glioma is a predictor of hypermutation at recurrence. Neuro Oncol 2020;22:1580-90.

22. Laub CK, Stefanik J, Doherty L. Approved Treatments for Patients with Recurrent High-grade Gliomas. Semin Oncol Nurs 2018;34:486-93.

23. Marenco-Hillembrand L, Prevatt C, Suarez-Meade P, et al. Minimally Invasive Surgical Outcomes for Deep-Seated Brain Lesions Treated with Different Tubular Retraction Systems: A Systematic Review and Meta-Analysis. World Neurosurg 2020;143:537-45.e3.

24. Trevisi G, Barbone P, Treglia G, et al. Reliability of intraoperative ultrasound in detecting tumor residual after brain diffuse glioma surgery: a systematic review and metaanalysis. Neurosurg Rev 2020;43:1221-33.

25. Zhou H, Wang K, Deng MQ. Factors affecting the quality of life of patients with malignant glioma after surgery. Practical Cancer Journal 2017;32:1470-1.

(English Language Editor: B. Draper) 